\title{
Impact Of Cognitive Profile And Information Uncertainty On Herding Behavior Of Investor
}

\author{
Dr. Taqadus Bashir ${ }^{1}$, Tajalli Fatima ${ }^{2}$, Hafsa Ilyas ${ }^{3}$, Amir Chudhary $^{4}$ \\ ${ }^{1}$ (Lecturer/ Faculty of management and administrative science/ University of Gujrat, Pakistan) \\ ${ }^{2,3,4}$ (MS Scholar/ Faculty of management and administrative science/ University of Gujrat, Pakistan)
}

\begin{abstract}
Primary objective of this paper was to investigate the impact of information uncertainty and cognitive profile of investors on herding behavior. We analyzed the behavior of investors influenced by the decision of other investors due to the lack of information and cognitive profile of investors. Well-designed experiments in three sessions are conducted for this study. These experiments were conducted in three stages to check the impact of different levels of information and conditions on the herding behavior. This study reflects that there is a positive relationship between the information uncertainty and the biasness of investor's behavior and occurrence of herding. Studies also reveal that the previously existing financial information and previously shown behavior in the market also encourages the herding phenomenon prevailing in the market. Researches indicate that the change in the Cognitive profile of the investors is more significant due to the increase in the financial information and the historical record of the transaction. There is also a significant change in the biasness of the investor due to the public information.
\end{abstract}

Keywords: Herding Behavior, investor behavior, information uncertainty, hearing impact, cognitive profile.

\section{Introduction}

Herding behavior is shown when investors intentionally or without knowingly imitate the behavior of other investors due to the information unavailability and other biasness factors, this type of behavior bias is evident through several studies (Sharma, 2001; Bellando, 2010; Merli, 2007; Liu, 2011; Chan, 2002). Investors imitate the behavior of others and don't rely on their own beliefs and neglect their personal preferences and show the herding behavior. Deliberate herding may be ineffective and is usually recognized by fragility and idiosyncrasy. It can cause to unwanted movements and wide spread danger. Therefore, it is essential to differentiate between real (intentional) and unwarranted (unintentional) herding. Furthermore, the causes of trader herding are essential for determining policy reactions for mitigating herd actions. Herding can be shown by observing others and form a coordination. Herding may lead the market to become unstable and increase in the vulnerability of the market. (Sharma, 2001)

This study considers the cognitive profile of different investors while showing herding behavior and will identify the true herding and spurious herding. These are two kinds of herding; "true herding or intentional herding" is deliberately shown by the investors by truly observing the actions of other investors, while the "spurious herding" is shown unintentionally and without knowing that other investors are performing the same action. Spurious herding is shown when the investors are sharing the same problem, same environment and same situation to be rational decision maker investors unconsciously shows the same behavior as other investors. (Sharma, 2001)

Investors when feel indifferent in any situation they show herding behavior to cope with the indifferent condition. Herding behavior is also shown by investors in the environment where the information limitation is prevailing. So, investors start imitating each other and form herds. It is noted that the both investors rational or irrational shown herding behavior when there is information limitation. (Bikhchandani, 2001) (Hirshleifer D. , 2001)

On the other hand, past studies also reveals that some rational investors while having sufficient information still show herding behavior, there are some other factors that encourages the investors to negate their private information and to make herd. While showing herding behavior investors don't know the quality of information of the other investors, they just form herds on the basis of their preferences and mind set (Parker, 2005). So that the investor's cognitive profile becomes a significant factor while the explanation of herding phenomenon.

To study this phenomenon empirically experiment based approach is used, this allows to erudite about the herding phenomenon in a controlled environment. The result of this study reveals that the information uncertainty is important in explaining the herding behavior, if the information factor diminishes and investor is well informed than its cognitive profile is the cause of his herding behavior. 
This paper is based on 5 sections, after this introduction 2nd section explains the previous studies about the drivers of herding. 3rd section explains the design and methodology of the empirical analysis. 4th section discusses the results of the analysis and the 5th section explains the conclusion of this paper.

\section{Literature Review}

Efficient market hypothesis explains that the all investors are equally informed of all the happening of the market and they rationally act upon the information interpreting it with same state of meanings. Likewise, if investors interpret the information with same state of meanings then the unavailability of the information leads to the same biasness and heuristics of individuals. Then the errors occur due to the information unavailability and systematic heuristic will almost be same. Investors simplify their decision by using systematic heuristics. Expected returns of the investors are effected the investors risk aversion behavior (Hirshleifer D. , 2001)

In the developing and emerging markets herding behavior is shown more than the well developed markets where the information symmetry is present. In the markets where the environment is uncertain, ambiguous and informational cascade is present more herding behavior can be evident. There is always a detail asymmetry between any client and provider, and some factor of an organization issue when entrepreneurs of resources assign investment decisions to expert managers (Sharma, 2001) evident this information cascade formation and herding phenomenon in different stock markets. (Sharma, 2001)

It is evident that the informational limitation is main driver of herding behavior while in the environment where the investor is more influenced by the behavior of others then his cognitive profile drives him to show herding behavior while depending upon the information of other investors. An experimental study conducted on the business graduate student with the three stages of information also concludes the dependency of herding behavior on uncertainty of information. (Beatriz Fernández, 2001)

\subsection{Motives of herding behavior}

Previous studies revealed that the investor's decision making is majorly affected by the information uncertainty factor and due to the cognitive setup up of the individual.

Information-based herding happens when experts absence confidence about their personal details and you can find (a lot of) doubt about the high quality of public details. As a impact, experts give up their personal indication (which is required to optimally upgrade the available information), and adhere to the herd that preserves an ineffective agreement. As such, the analysts' activities are uninformative to later experts and a stream happens that 'blocks' the inflow of new information (Hirshleifer D. \&., 2003)

A huge number of researchers of this action concentrate on the question of whether, in function of the available information, herding is obvious in the market or not. Many studies of the source of this trend concentrate on the actions of finance supervisors and analysts. In this case, writers concentrate on logical herding considering settlement systems and issue for popularity to be accountable for the use of herding.

Rational traders merge different resources using Bayes rule: the weights placed on the different items of details should be proportionate to their respective precision. The traditional strategy in fund is that only results issue. Following this strategy, behavior tendencies terminate out in the aggregate because either they are averaged out or they are fixed for by logical arbitrage. (Daniel, 1999)

If one has access to public and personal information and they are of equivalent value in predicting the asset's intrinsic value the person would put equivalent weight on personal and public signals. When the person knows that others have also observed the same public indication, the community indication is a better predictor of average opinion. He will put more weight on the public indication than on the personal indication. If individuals' desire to pay for an resource is relevant to their objectives of regular viewpoint, then we will have resource prices overweighting community details comparative to the personal details. (Allen, 1993)

Researches shows that the degree of uncertainty of information is linked with the perception of the investors and it's believe on its information, so it can be concluded that

H1: Herding behavior is shown more in the highly uncertain situations.

\subsection{Cognitive profile}

Well known of activities negates asymmetric details in the feeling that agents would have were in the same way without the personal part of their information. However, the literary works also identifies that investors' feeling that other traders are better advised than they are is major in motivating them to ignore their personal details and to mimic other investors' choices. Investors who imitate do not know the high quality of other investors' details, economical industry styles thus being depending on the feelings of traders and not on logical responses. Therefore, the investors' intellectual information becomes an important explanatory aspect and cognitive profile of the herding trend.

Topics show less repent when the prejudice impacts a lot of individuals (regret bias). Consequently, herding actions will rely not only on the doubt existing in the market, but also on each investor's personal 
understanding about the stage of doubt surrounding them. in the same informative perspective traders who are more vulnerable and less assured about their resources will have a greater tendency to herd. This sensation of doubt is an attribute of each individual, since it is determined by each person's behavior, their more or less intuitive character, their risk propensity, their unwanted or deficiency of assurance, their illusion of control, their level of patience for indecisiveness and level of tolerance to ambiguous situation, and so on. All these factors, which are related, make up the investor's intellectual information, which decides how the individual gets and translates the different information stimulating elements they get from their atmosphere. Consequently, individuals' intellectual information and cognitive make up will also be determinant in describing in what conditions traders choose to neglect their personal information and replicate greater part choices in the market. (Beatriz Fernández, 2001)

Acknowledging the importance of the intellectual information in describing herding actions, the difficulty now can be found in how to measure this information and consequently represent it in variables. This problem is settled by using the tendencies in individuals' actions and the rules of thumbs as proxy servers of the intellectual information. The literary works recognizes a wide range of tendencies and guidelines, which develop in individuals' need to make simpler their decision problems because of their intellectual limitations and feelings. (Hirshleifer D. , 2001)

Herding behavior can be linked up with the different biases like illusion of control, overconfidence, selfattribution, and hot-hand and gambler's fallacies. Investors can show herding behavior due to these behavior biases and their impact on the thoughts of the individual while making investing decisions. (Hirshleifer D. \&., 2003)

Overconfidence happens when topics consistently overestimate their potential to resolve circumstances as opposed to relax of the people, overvalue their choices and overestimate their own knowledge. Trader overconfidence can produce strength in inventory profits and this strength is likely to be most powerful in those shares whose appraisals need the interpretation of uncertain information. (Daniel, 1999)

When individuals look back and evaluate their quotes and choices, they are generally impacted by a sequence of tendencies known as hindsight prejudice, such as self-attribution. Self-attribution prejudice and self-attribution bias prevails when the person features activities that confirm their activities to their own expertise and activities that do not confirm their activities to exterior agents. Thus, people impacted by self-attribution will not replicate others unless they have had a lengthy run of inadequate decisions.

Almost usually, the individual information handling prejudice that underlies a given design of industry ineffectiveness is a variation of the representativeness heuristic. The representativeness heuristic happens when a individual determines the prospect of a meeting in operate of the level to which it is identical in its important features to a inhabitants. Representativeness heuristic gets more room in doubt. The tendencies committed when using the representativeness heuristic consist of the gambler's misconception, whereby the person represents that the long run unique actions of a resource actually depends on its past performance. (Kahneman, 1974)

It can be concluded that as the information increases investors more depend upon its cognitive decision making and its follow its intuition and emotions to make rational decisions and to risk averse.

$\mathrm{H} 2$ : Investor's decision making is dependent upon its cognitive profile that may be defined as combination of biases, its feelings and herding behavior.

Topics show less repent when the prejudice impacts a huge variety of people (regret bias). Consequently, herding actions will rely not only on the uncertainty present in the marketplace, but also on each investor's personal understanding of the stage of uncertainty around them. Thus, in the same informative perspective traders who are more vulnerable and less assured about their resources are more likely to herd. This sensation of doubt is a attribute of each individual, as this will depend on each person's behavior, their more or less intuitive traits, their risk bearing tendency, their unwanted or deficiency of confidence, their illusion of control (ILC), and their level of tolerance for indecisiveness and ambiguity. All of these factors, which are related, make up the investor's intellectual information, which decides how the person gets and interprets the different details stimulating elements to appear from their atmosphere. Consequently, individuals' intellectual information will also be determinant in describing in what circumstances traders choose to neglect their personal details and to imitate majority choices in the market.

\subsection{Behavioral biases and their detection}

Having recognized the value of intellectual information in herding behavior, the difficulty now can be found in how to measure this information and consequently represent it in factors. This problem is settled by using tendencies in individuals 'behavior and guidelines as the detectors of the intellectual information and cognitive make up of individuals. The literary works recognizes a wide variety of tendencies and guidelines which develop in individuals' need to simplify their decision problems due to their intellectual restrictions and emotional tendencies. (Hirshleifer D. , 2001) 
This study aims to recognize the effect of the cognitive make up and its impact on the herding behavior shown by them. In this study over confidence bias, illusion of control bias, self attribution bias and gambler's fallacy and hot hand fallacy are considered to analyze the cognitive make up of the investors. These biases are considered to find the impact of these factors on the investors herding behavior.

ILC illusion of control is the bias due to which individual think that they may control or may influence the events. While showing this biasness they underestimate the chance of occurrence and fate. They surely believe on their selves and overestimate their ability to have an impact on the events. (Kahneman, 1974). Thus, these traders infer details from the options taken by other individuals, supposing that the latter's options have been created depending on relevant information and not arbitrarily. The only substitute supposition is that they are making clearly invalid options. Since individuals more topic to ILC are inspired to give meaning to others' actions in a way that is easy to understand and foreseeable, this latter Investors' cognitive profile alternative is less likely. Thus this factor strongly influence herding positively and investors with this trait shows herding.

Over Confidence (OC) happens when topics consistently overestimate their potential to resolve situations in comparison to other people, overvalue their choices, and overestimate their own knowledge. OC is usually more powerful for more dissipate projects for which feedback is slowly than for more technical projects that offer immediate outcome. OC negatively affect herding and investors with the over confidence bias do less herding.

When people look back again and evaluate their quotes and choices, they are generally impacted by a sequence of tendencies known as hindsight prejudice, and self attribution bias (SA). SA bias exists when the person features activities that confirm their activities to their own skill and activities that do not confirm their activities to exterior agents. (Fischhoff, 1982) Investors how have shown a poor performance in the past more show herding behavior while investors with better performance in the past make less herds.

Gambles fallacies are a type of representative heuristics. Almost usually, the human information handling prejudice that underlies a given design of industry ineffectiveness is a variation of the representativeness heuristic". The representativeness heuristic occurs when a individual determines the prospect of a meeting depending on the level to which it is similar in its important features to a population. $\mathrm{n}$ the gambler's fallacy (GF), the topic views randomness as a self-correcting procedure in which a difference in one route causes a difference in the other to recover the equilibrium. (Kahneman, 1974) However, individuals who anticipate too few lengthy lines in unique series, think that those lines are not validated by mere chance and are vulnerable to the hot-hand fallacy. This factor dominantly positively affects herding behavior.

So the hypothesis for these all biases can be,

H2A. ILC bias positively affects herding.

H2B. OC bias negatively affects herding.

H2C. SA bias negatively affects herding.

H2D. HHF positively affects herding.

H2E. GF negatively affects herding.

\section{Experimental Aim and Design}

Herding behavior is based on the irrational behavior of investor due to the information uncertainty. Bikchandani and Sharma argue that to examine herd behavior of investor most appropriate method is to observe a group of investors trading together actively and simultaneously in a similar situation.(Bikhchandani, 2001) . While studying the herding behavior in the past a study conducted by the (Bikhchandani, 2001) was based on the three experimental sessions that shows the rational herding of the investors. Two of the experimental sessions were conducted on the agents and traders that invest the money of others and they invest on behalf of the others. Same private information was provided to all the participants of the third session while in the experimental sessions for this paper subject where the university students and the information that is provided to them in the second session was not the same that makes them indifferent while making their investments.

\subsection{Sample}

In this study two experimental sessions are conducted to examine the herd behavior of investors. Our sample consists of 70 business administration students studying in the final year of their degree. Initially knowledge about the finance is provided to them. Then the questionnaire about their demographics is filled with them.

\subsection{Experiment}

Two sessions of experiments are conducted for this study. The first session find out the relationship between the herding behavior and the information uncertainty effect. In the second session different level of information is provided to the investors and its effect is studied on the investors. Different behavioral biases influences the behavior of investors while the provision of information. 
All the experimental sessions are conducted in the controlled environment of the laboratory and a sample of 70 people participated in the experimental sessions. All the participants were the business administrative students.

Student's behavior with the comparison to the professional investors is somewhat different but, they both form herds while trading. Many studies reveal the facts about the herding behavior of both the students and professional traders.

- It can be explained that the market professionals show less biasness than the finance students (Alevy, 2007)

- Herd is formed equally by the marker professionals and the finance students.

All the experiments are conducted in the laboratory controlled conditions. These experiments are beneficial as the public and private information can be controlled and this will make enable to test the herd behavior more easily. (Alevy, 2007)

These experiments and field research enable to study the important factors relative to the herding behavior of investors. Experimental study is the most pertinent method to examine the herding behavior by separating the cause and effect of behavior and individually examining the behavior and its cause. Experiments based on the theory also provide the unique knowledge about the financial decisions of the investors in different conditions. (Raghubir, 1999)

Participants of both the sessions were awarded with the gifts through the lottery. Lottery was based on the random withdrawal of the participant's name.

Experimental session I: herding behavior and information uncertainty

As details available to traders is connected to the level of doubt they perceive and how the details is provided, in Period I, the impact of these aspects on investors' herding actions is evaluated. Investors may show herding behavior while buying, selling, trading new security and while participating in the market. (Hirshleifer D. \&., 2003)

In our research, topics are compensated more if they act rationally, significance they acknowledge that changes in the rates of stock is unique and they implement Bayes' concept. As the price proposed in each deal is the asset's predicted value given the record of deals, the rational trader will choose do nothing in each circular. It is observed through the study that the as the more public information is provided to the investor they become more ambiguous about their own information and trust less on their own informational knowledge and become more insensitive to the internal signals of the information. (Hirshleifer D. \&., 2003)

\subsubsection{1st session, 1st stage}

To test the 1st hypothesis based on the uncertainty information effect on the herding behavior a study based on three stages if information is conducted. Therefore, to analyze the hypothesis regarding the regards between details doubt and the herding trend, the writers recognized three therapies that vary in the quantity of community information available. Each of the therapies reproduces different stages of community information (Table I). In the first therapy - "high uncertainty" - public information details comprises only of the stock's prices in past times (transactions). The cost details are calculated following Bayes rule.

\subsubsection{2nd stage, 3rd stage information}

In the second therapy - "moderate uncertainty" - traders have public information details about the costs in the previous transactions and details about the investors' real decision: purchased, marketed or did nothing. Lastly, in the "low-uncertainty" therapy, traders have community information about the stock prices in the past dealings, the real dealings performed, and the analysts' agreement suggestions. These suggestions are produced randomly because the appropriate point is the accessibility to details offered by specialists. The analysts' encounter in the market may mean that members understand them to be a source of efficient information. Therefore, doubt decreases from therapy to treatment as the public information details available to the traders improve.

Spurious herding may contaminate the results so to decrease this factor of herding private information is provided to some specific people. Private information is based on the face value of the stock and it remains same for all the three stages of the session. Different private information about dividend declaration, stock split, stock issue, IPO's and other unfavorable information were provided to some participants. It depends on the cognitive profile of the investors that how they take the information as they take it favorable or may take it unfavorable. According to the cognitive make up of the investor they may act upon the information and may avoid it and depending more on the others and form herd. Participants must decide whether to buy or sell a stock, or do nothing, given the rate and the public and personal information provided.

During the sessions price may rise when the stocks are more bought by the investors and the price decreases when the investors sell out their stocks. A clear fluctuation is shown in the stock while the sessions and the behavior of the investors are then observed. 
The previous history of a different variety of past dealings in each circular allows us to assess the impact of the moment at which topics must decide: at the starting or at the end of the industry. Thus, when the variety of past dealings is low, three or four, traders choose when the industry reveals, whereas when the variety of transactions is great, from five to nine, traders take their choices when the industry ends. If the number of past dealings shows details, those who choose at the closing period of the market can use the details offered by the variety of dealings.

When both types of details - public information and personal - generate the person to take the same choice, it is difficult to decide which type of details has had the greatest weight in the person's choice taking. In other terms, it is difficult to know whether the person has replicated the other investors' choices or followed their own personal details. These circumstances only act as a control, enabling the researchers to make sure that the members react coherently; they cannot consider them in the subsequent research of herding behavior. Only when the public details about the behavior of others and the personal details generate the trader to take reverse decisions and the trader chooses to adhere to the public details giving up their own private information can deliberate herding be said to be available. Therefore, we consider that an individual reveals an apparent purpose to mimic the actions of other traders when, ignoring their own personal details, they take the same choice as most of their forerunners.

The majority's choice in one particular circular is the one that appears at least two periods more than the relax of choices. For example, in a circular where two people marketed and four people purchased, and the individual chooses to buy, despite being led to offer by their own personal details, we determine that this is participant replica. In purchase to evaluate the regards between herding actions and stage of information uncertainty, each person's percentage of replica in each therapy was calculated taking into consideration only those circumstances that leave out the likelihood of spurious herding.

Experimental Session II: information uncertainty, behavioral bias and herding:

Session two was conducted to find out the different biases found in the investors due to the cognitive makeup of the investors. The research views how UR to new details impacts herding programmed by information doubt. To recognize how the topics existing the suggested tendencies we design to analyze the choices questionnaire. (see appendix) Some of the concerns involved in our analysis of choices are a choice of questions included in the documents estimated, customized to take into consideration the surroundings of the subjects in the research. The rest of the concerns are new with the objective of introducing theoretical concerns relevant with our document. This analyze provides the participants with different real-life circumstances in which they have to choose which of the proposed actions to take.

With the aim of looking further at the regards between the factors calculating the behavioral tendencies and herding actions, the scientists first performed an research of variance (ANOVA) and then a binary logistic regression (LOGIT). We are conscious that the cognitive factors are not mutually unique, and because of this the latter analysis allows us to consider the interrelations between the intellectual factors selected in the present research.

\section{Results}

During the experiment at the 1 st it was found that as the informational uncertainty decreases the herding phenomenon start diminishes. When only the stocks without any public or insider information offered traders were forming more herds and were more neglecting their own information. Value of the mean for the stage 1 is 1.7.Less herding trend than before was observed at the 2 nd stage of the information uncertainty test when historical trend with the past transaction and publically available data was provided. Mean value for the moderate information uncertainty stage is 1.15 . At the last stage of the information uncertainty test when the insider information provided to the investor herd behavior significantly reduced and its mean value is .655 (see table 1). As a result hypothesis H1 that hypothesize herding behavior is shown more in the highly uncertain situations is accepted.

Statistics
\begin{tabular}{|ll|l|l|l|}
\hline \multicolumn{2}{|c|}{} & high & moderate & low \\
\hline N & Valid & 70 & 70 & 70 \\
& Missing & 1 & 1 & 1 \\
Mean & & 1.7401 & 1.1524 & .6553 \\
Std. Deviation & .61377 & .53780 & .50723 \\
Variance & .377 & .289 & .257 \\
Skewness & -.407 & -.337 & .532 \\
Std. Error of Skewness & .287 & .287 & .287 \\
\hline
\end{tabular}




\section{Conclusion}

The intellectual details of the topics shows more appropriate in the low-uncertainty treatment, when there are several resources and traders know that only a few dealings took position before they had to take their choices. Three of the variables are significant: ILC, SA and OC. The associated symptoms indicate that people allocated to the high-intensity replica prevent display greater stages in ILC and OC, and a reduced level of SA. In other terms, in this therapy and with just a few dealings, the ILC and OC biases have a beneficial regards with the herding trend, while the SA prejudice has an inverse regards with this actions.

Investors' herding actions in marketplaces arises from informative restrictions. Either traders absence part of the details or are not able to process the information available and convert it into information. In an unclear atmosphere, where perfect information does not are available, the sensation of doubt brings individuals to think that others are better advised. The higher the investors' sensation of question, the more they question their own details. Consequently, in unclear surroundings, investors try to acquire details by monitoring the financial decision taking of others participating in the marketplace. Traders feel particularly forced to mimic others when they notice only a few past dealings in the marketplace. The reduction that follows from this is that the higher the level of question, the higher the investors' propensity to imitate other individuals' choices.

The outcomes acquired in the research performed here provide new evidence regarding the aspects all the surrounding in the herding trend in marketplaces. They show that doubt, and consequently informative restrictions, prefers herding among investors. Results display that in the high- and moderate-uncertainty therapies, personal variations cannot consideration for the different strength stages of replica among individuals. They also display that details doubt in addition to the provision of information on a number of past dealings homogenizes individual actions with regard to the herding trend.

Two conclusions may be attracted from this research: first, there is a dependency relation between the sensation of doubt, investors' actions tendencies and the herding phenomenon. Second, the factors of herding information and actions tendencies - are related. Particularly, the use of high stages of doubt prefers herding behavior regardless of the variations in the actions tendencies of people. Only when the stage of doubt drops and the number of dealings formerly performed in the market is low is the impact of the actions tendencies determinant in investors' herding behavior.

The present results validate that the herding trend is complicated, since aspects of a very different characteristics get involved.

\section{References}

[1] Alevy, J. H. (2007). "Information cascades: evidence from a field experiment with financial market professionals". The Journal of Finance

[2] Allen, F. S. (1993). Finite bubbles with short sale constraints and asymetric information. Journal of Economic Theory

[3] Beatriz Fernández, T. G.-M. (2001). the role of the interaction between information and behavioral bias in explaining herding. Departments of Financial Economics and Accounting, and Management .

[4] Bellando, r. (2010). Measuring Herding Intensity: a Hard Task. * Laboratoire d'Economie d'Orléans .

[5] Bikhchandani, S. a. (2001). "Herd behavior in financial markets". IMF Staff Papers .

[6] Chan, W. F. (2002). Testing behavioral finance theories using trends and sequences in financial performance. MIT Sloan School of Management, Working Paper No. 4375-02,

[7] Daniel, K. a. (1999). "Market efficiency in an irrational world. Financial Analysts Journal

[8] Fischhoff, B. (1982). For those condemned to study the past: heuristic and biases in hindsight. Cambridge University Press, Cambridge .

[9] Hirshleifer, D. \&. (2003). Herd Behaviour and Cascading in Capital Markets. European Financial Management .

[10] Hirshleifer, D. (2001). Investor Psychology and Asset Pricing. Munich Personal RePEc Archive .

[11] Kahneman, D. a. (1974). Judgment under Uncertainty: Heuristics and biases. Science .

[12] Liu, C. (2011). Herding Behavior in Bank Lending: Evidence.

[13] Maxime Merli, T. R. (n.d.). What drives the herding behavior of individual investors?

[14] Raghubir, P. a. (1999). A case for theory-driven experimental inquiry. Financial Analysts Journal

[15] Sharma, s. b. (2001). Herd Behavior in Financial Markets. IMF Staff Papers . 